\title{
Maedi-Visna virus: current perspectives
}

This article was published in the following Dove Press journal:

Veterinary Medicine: Research and Reports

\section{Esperanza Gomez-Lucia Nuria Barquero Ana Domenech}

Department of Animal Health, Faculty of Veterinary Medicine, Complutense University, Madrid, Spain
Correspondence: Esperanza Gomez-Lucia Department of Animal Health, Faculty of Veterinary Medicine, Avda. Puerta de Hierro, s/n, Complutense University, 28040 Madrid, Spain

Tel +34913943718

Email duato@ucm.es

\begin{abstract}
Maedi-Visna virus (MVV) and caprine arthritis-encephalitis virus are commonly known as small ruminant lentiviruses (SRLVs) due to their genetic, structural, and pathogenic similarities. They produce lifelong lasting infections in their hosts, which are characterized by slow progression till overt disease happens. There are four major clinical forms derived from a chronic inflammatory response due to the constant low grade production of viruses from monocyte-derived macrophages: respiratory (caused by interstitial pneumonia), mammary (which may produce a decrease in milk production due to subclinical mastitis), joint (characterized by lameness), and neurological (characterized by chronic nonpurulent meningoencephalomyelitis). There are three levels which try to eliminate the virus: cellular, body, and the flock level. However, SRLVs have ways to counteract these defenses. This review examines some of them.
\end{abstract}

Keywords: small ruminant lentivirus, molecular biology, immune response, genetic resistance

\section{Introduction}

The viruses that produce Maedi-Visna virus (MVV) and caprine arthritis-encephalitis virus (CAEV) are known as small ruminant lentiviruses (SRLVs) due to their structural, genetic, and pathogenic similarities. In addition, molecular studies have shown that both viruses represent a broad spectrum of variants that can affect both animal species ${ }^{1}$ and certain viral variants that normally affect sheep can infect goats, and vice versa ${ }^{2}$ or even predominate in the other species. ${ }^{3,4}$ Nevertheless, infection by MVV is more common in sheep and infection by CAEV is more common in goats, so homologous transmission is probably favored. The ability of the SRLVs to produce cross-infections, jumping the interspecies barrier, is unusual, as most lentiviruses have a very limited capacity to grow in cells not from their host species.

Maedi-Visna (MV) is a sheep disease characterized by respiratory (Maedi, determined by interstitial pneumonia) and nervous (Visna, progressive inflammatory disease of the central nervous system) clinical signs and occasionally of the joints and/or mastitis. Caprine arthritis and encephalitis (CAE) is the name of the disease in goats, as the joints and nervous system are most often affected. Both diseases are slow progressing and usually subclinical.

MVV and CAEV infections are widespread worldwide. MVV has recently been identified in Japan, a country that was considered exempt. ${ }^{5}$ So far, MVV-free (but not CAEV-free) countries are New Zealand and Australia. The prevalence is much higher in developed countries, which seems to be related to the system of feeding lambs or 
kids with a pool of colostrum or milk from the tank, a practice that favors transmission, ${ }^{6}$ and to the management system. ${ }^{7,8}$

The route of transmission is related to body fluids, mainly respiratory exudates and milk or colostrum, which may contain infected monocytes and macrophages. ${ }^{9}$ The main transmission routes are airborne, favored by overcrowding (stabling), ${ }^{7}$ and milk borne. ${ }^{10,11}$ It is not clear if the transmission among animals occurs through the presence of free virions and/or through infected cells. Other modes of transmission such as the transplacental and through semen are less important from an epidemiological point of view. ${ }^{1}$ The potential risk linked to the milking machine and the needle has not been tested. Regardless of the route of transmission, the viruses cross the mucous barriers and infect resident macrophages and dendritic cells. ${ }^{1}$

Both MVV and CAEV belong to the family Retroviridae, genus Lentivirus. The SRLVs are currently classified according to their phylogenetic relationships in the following five groups: A, B, C, D, and E. ${ }^{12}$ Genotype A includes strains of MVV; genotype $\mathrm{B}$ includes strains of CAEV; genotype $\mathrm{C}$ corresponds to SRLV isolated from Norwegian sheep and goats; genotype D has been identified when analyzing pol sequences of SRLV of Spanish and Swiss sheep; and genotype $\mathrm{E}$ has been isolated in Italy. ${ }^{13}$

MVV and CAEV particles measure between 90 and $120 \mathrm{~nm}$ in diameter and consist of the envelope and the core. The envelope is formed by a membrane bilayer of host cellderived phospholipids, in which viral-encoded glycoproteins are inserted. The core or capsid is a protein case, which contains the viral RNA and the enzymes necessary for viral replication. As other retroviruses, virions contain two linear molecules of RNA. The single-stranded RNA molecules are transformed into double-stranded DNA (dsDNA) using the enzyme reverse transcriptase (RT); thanks to this mechanism, the retroviral genome (known as provirus when it is dsDNA) can be inserted into the genome of the host cell (Figure 1).

The genomes of MVV and CAEV are between 8,400 and 10,000 nucleotides (nts) long and consist of three main genes common to all replication-competent retroviruses, such as gag, pol, and env, and several regulatory genes. Proviral DNA is flanked by repeated sequences known as long terminal repeats (LTRs) containing promoter elements that initiate the transcription of $\mathrm{DNA}^{14}$ and play an important role in cellular tropism ${ }^{15-17}$ and in pathogenesis. ${ }^{18,19}$ Gene gag encodes the internal structural proteins, which protect the DNA. The largest is the capsid protein (p25CA), which stimulates the production of antibodies in the host, for which it is used in Enzyme Linked ImmunoSorbent Assay (ELISA) methods. The other two are the matrix (p16MA) and the nucleocapsid (p14NC) proteins. Gene pol encodes the enzymes that are involved in replication and DNA integration, namely protease (PR), RT, dUTPase, and integrase (IN). Finally, env encodes the following two types of proteins inserted in the envelope: the surface (gp135SU) and the transmembrane (gp46TM) glycoproteins. SU contains domains that are recognized by the cell receptors to allow entry into the cell. It stimulates the production of antibodies and is also genetically variable, so modifications in SU determine the antigenic variability of the

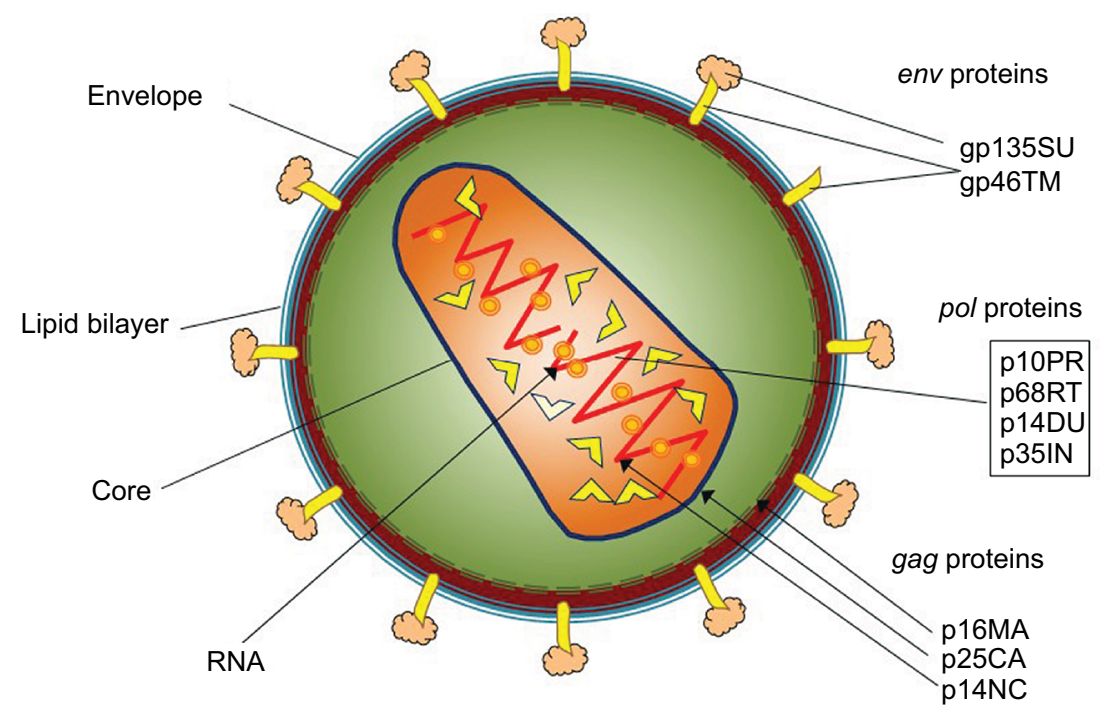

Figure I Schematic representation of an SRLV particle.

Notes: The viral genome, along with the enzymes necessary for transcription, integration, and maturation, is encapsidated inside the core formed by capsid proteins. This is surrounded by the matrix and by the lipid bilayer in which the envelope glycoproteins are inserted.

Abbreviation: SRLV, small ruminant lentivirus. 
different isolates. TM, which has fusion capacity of lipid membranes (allowing the fusion between the viral envelope and the membrane of the host cell), is a much more conserved protein. For this reason, it is a good candidate to be used in ELISA techniques functioning in different geographic locations. ${ }^{20,21}$

Accessory regulatory genes are located coinciding with the regions pol and env in different reading frames and contain information for the synthesis of proteins that regulate viral replication. These genes are as follows:

- vif, the product of which is necessary to make the virus infectious, ${ }^{14,22-25}$ identified as an important factor to fight against the defense mechanisms of the cell;

- $v p r$-like, which has a function similar to that of $\mathrm{Vpr}$ in other lentiviruses, although initially it was considered equivalent to Tat protein in other lentiviruses, but no clear transactivation function has been associated to it; ${ }^{26}$ and

- rev, which is involved in the regulation of viral expression (Figure 2).

In this review, we focus on three levels of the infection by SRLVs: the cellular level, the body level, and the herd level.

\section{SRLV infection of the cell - if allowed}

It is possible that MVV and CAEV use different cell receptors to penetrate the host cell. ${ }^{1,16}$ Recent studies have identified a mannose receptor, which seems to be the cellular receptor in sheep. ${ }^{27}$ Once the virus enters the cell, the replication mechanism is similar to that of other retroviruses, integrating the dsDNA in the host genome as outlined earlier, which produces a lifelong infection. Viral proteins and genomic RNA are synthesized from the integrated DNA, using the enzymatic systems of the host cell. Finally, the viral envelope is formed from the lipid cellular membrane, which incorporates the glycoproteins gp135SU and gp46TM.

It may seem that the virus always succeeds in infecting the cell, but this is not always true. The cell fights SRLV infection with a variety of mechanisms. Once the virus enters the target cell, molecules of the innate and adaptive immunity start host restriction. Innate immunity molecules, eg, tripartite motif-containing 5 (TRIM5), bind viral capsids, inhibiting integration and postintegration steps of the virus cycle, while others, eg, Apolipoprotein B mRNA-editing catalytic polypeptide-like 3 (APOBEC3 or A3), mutate the viral genome. Thus, lack of productive infection is not due only to the lack of functional receptors, since postentry restriction factors may also be responsible. However, retroviruses are able to counteract these mechanisms.

\section{TRIM5}

The TRIM5 family members bear a common structure consisting of a RING finger zinc-binding domain, a B-box zincbinding domain, followed by a coiled-coil structure (with E3 ubiquitin ligase activity). ${ }^{28}$ The TRIM5 $\alpha$ isoform, which is active against retroviruses, contains a $\mathrm{C}$-terminal PRYSPRY domain that binds the retroviral capsid CA. TRIM5 $\alpha$ recognizes motifs within the capsid proteins, removes them, probably by proteasome-dependent degradation, and interferes with the uncoating process, therefore preventing successful reverse transcription and the continuation of the viral cycle.
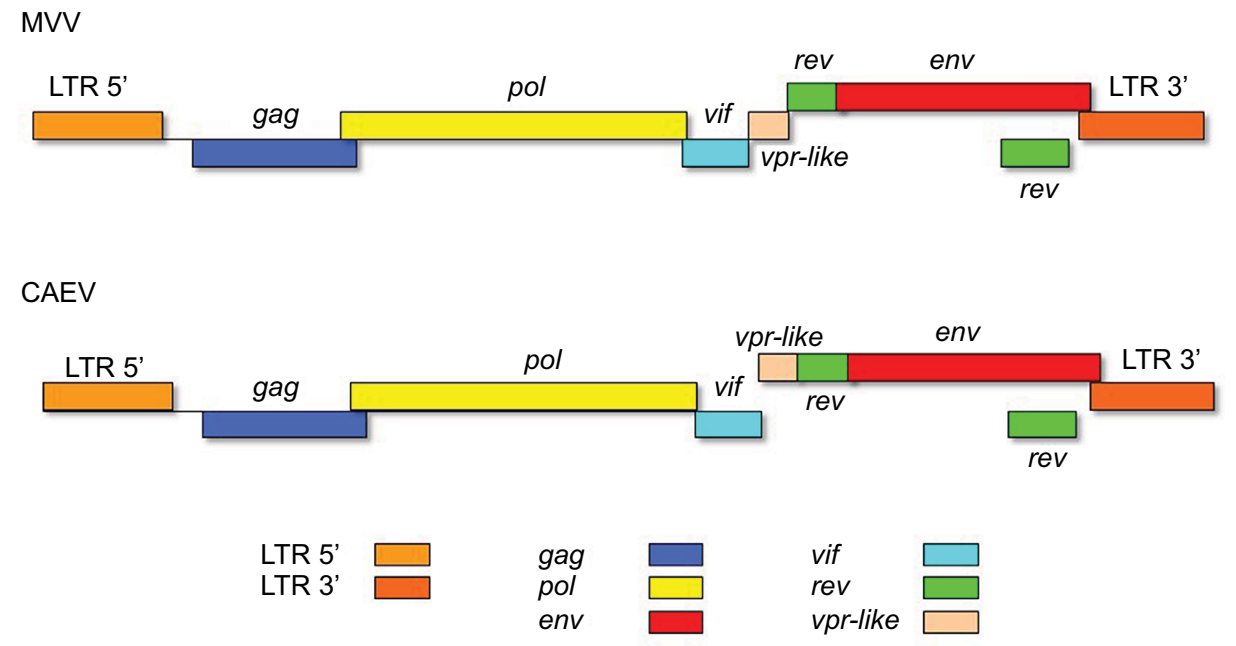

Figure 2 Schematic representation of the gene distribution in the proviral genomes of MVV and CAEV.

Notes: In the provirus, the viral DNA is flanked by the LTR, which governs transcription of the genome. In the image, the essential genes are shown in the middle and the accessory genes are shown on the right.

Abbreviations: CAEV, caprine arthritis and encephalitis virus; LTRs, long terminal repeats; MVV, Maedi-Visna virus. 
Recently, it has been shown that TRIM5 $\alpha$ can restrict MVV in a similar way to other retroviruses. ${ }^{28}$

\section{APOBEC3/Vif}

In recent years, much attention has been paid to the APOBEC3/Vif system, prompted by observations in human immunodeficiency virus (HIV). The A3 proteins appear to exert their inhibitory activity mostly through a deaminasedependent mechanism, which deaminates cytosine to uracil. In this way, A3 proteins insert G-to-A hypermutations in newly synthesized viral minus-strand DNA (viral cDNA) after the clearance of RNA from the DNA/RNA hybrid (Figure 3). ${ }^{29} \mathrm{~A} 3$ incorporated into virions (passenger A3) is the main cause of deamination evidenced by viral reverse transcripts displaying a high frequency of G-to-A mutations. ${ }^{30}$ These mutations cause abnormal expression of nonfunctional viral proteins, resulting in disruptions of the viral life cycle. Recently, it has been shown that sheep (Ovis aries) have the following three A3 different genes: APOBEC3Z1 (A3Z1), APOBEC3Z2 (A3Z2), and APOBEC3Z3 (A3Z3), ${ }^{25,31}$ the antiviral effect of which is counteracted by Vif of MVV.

As mentioned earlier, Vif is an accessory protein of lentiviruses. MVV Vif is essential for the infection of primary macrophages and for in vivo infections..$^{22,32}$ It degrades APOBEC3 proteins through a ubiquitin/proteasomedependent pathway, ${ }^{24}$ by recruiting certain cellular proteins to construct a Vif-mediated E3 ubiquitin ligase complex. These cellular proteins in sheep include the scaffold protein Cullin5 (CUL5) and the substrate adaptors Elongin B/C $\mathrm{C}^{25}$ and CYPA (also known as peptidylprolyl isomerase $\mathrm{A}$ ), as cofactors for degrading the sheep APOBEC $3 .{ }^{24,33}$ All these induce $\mathrm{A} 3$ polyubiquitination and degradation, thereby suppressing A3-mediated antiviral activity ${ }^{34}$ because it cannot be incorporated into the virion. ${ }^{30}$ Zinc does not seem to be

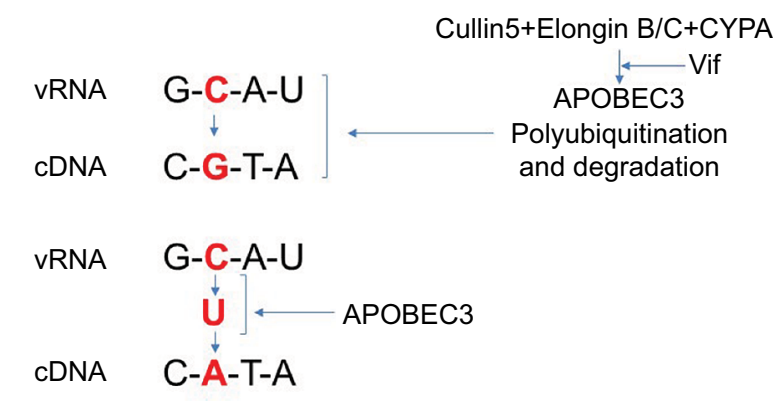

Figure 3 Mechanism by which APOBEC3 induces G-to-A mutations and counteraction by SRLV Vif.

Notes: APOBEC3 produces deamination of $C$, leading to $U$, which is reverse transcribed into A. However, SRLV Vif is able to degrade APOBEC3, circumventing this defense mechanism.

Abbreviation: SRLV, small ruminant lentivirus. important for the activity of MVV Vif. ${ }^{25}$ The effect seems to be related to the type of cell, since it has been found that A3Z1 downregulation (but not the others) correlates with increased viral replication in monocyte-derived and M2-polarized macrophages, but not in monocytes and M1 macrophages. ${ }^{30}$

\section{Interferons (IFNs)}

Another system by which the cell rejects viral infection is IFN. IFNs are cytokines produced in response to viral infection, which produce the so-called antiviral state of the cell. The following three types of IFNs have been identified in small ruminants: type-I (IFN-I), which includes IFN- $\alpha$, IFN$\beta$, and several others (IFN- $\omega$ and IFN- $\tau$ ), produced by most virus-infected cells; type-II (IFN-II), which includes only IFN- $\gamma$ and is produced only by certain cells of the immune system; and type-III (IFN-III), including IFN- $\lambda$, which were former interleukins. To trigger the antiviral response, IFNs bind specific receptors on the cell membrane, IFNAR1 and 2, that activate signal pathways rendering proteins that cross the nuclear membrane and bind to the DNA, in sites or sequences called IFN-sensitive response elements (ISREs) in the case of IFN-I, or gamma-IFN activation site (GAS) in the case of IFN-II. This causes the transcription of genes, which fight viruses through different mechanisms, and the consequence is a rejection of the viral infection by the cell (Figure 4). ${ }^{35}$

Several studies have shown that the U3 region of the LTRs that flank the proviral DNA genome mentioned earlier contains a high number of sites, which bind cellular factors, activating transcription (transcription-binding sites [TBS]). Among them, SRLVs contain ISRE and GAS. ${ }^{36-39}$ Thus, when the cell is activated by IFN and the signal reaches the nucleus, cellular molecules bind these TBS, modulating transcription. A functional ISRE has also been identified in 5' HIV LTR, a lentivirus closely related to SRLVs. In HIV, ISRE activation probably plays an important role in the early phases of viral infection as a strategy to counteract IFN-mediated host defenses. ${ }^{40}$ Our group also found a dosedependent response to IFN-I (IFN A/D) in cells transfected with a plasmid including the LTR of MVV and a reporter gene, the green fluorescent protein (GFP), in the sense that less fluorescence was evidenced with the exposure to lower amounts of IFN, suggesting that IFN stimulates viral expression directed by the LTR. ${ }^{41}$

\section{The virus spreads - and the body reacts}

If the virus is able to overcome these restriction mechanisms, there is a short phase of viremia. At this stage, there are 


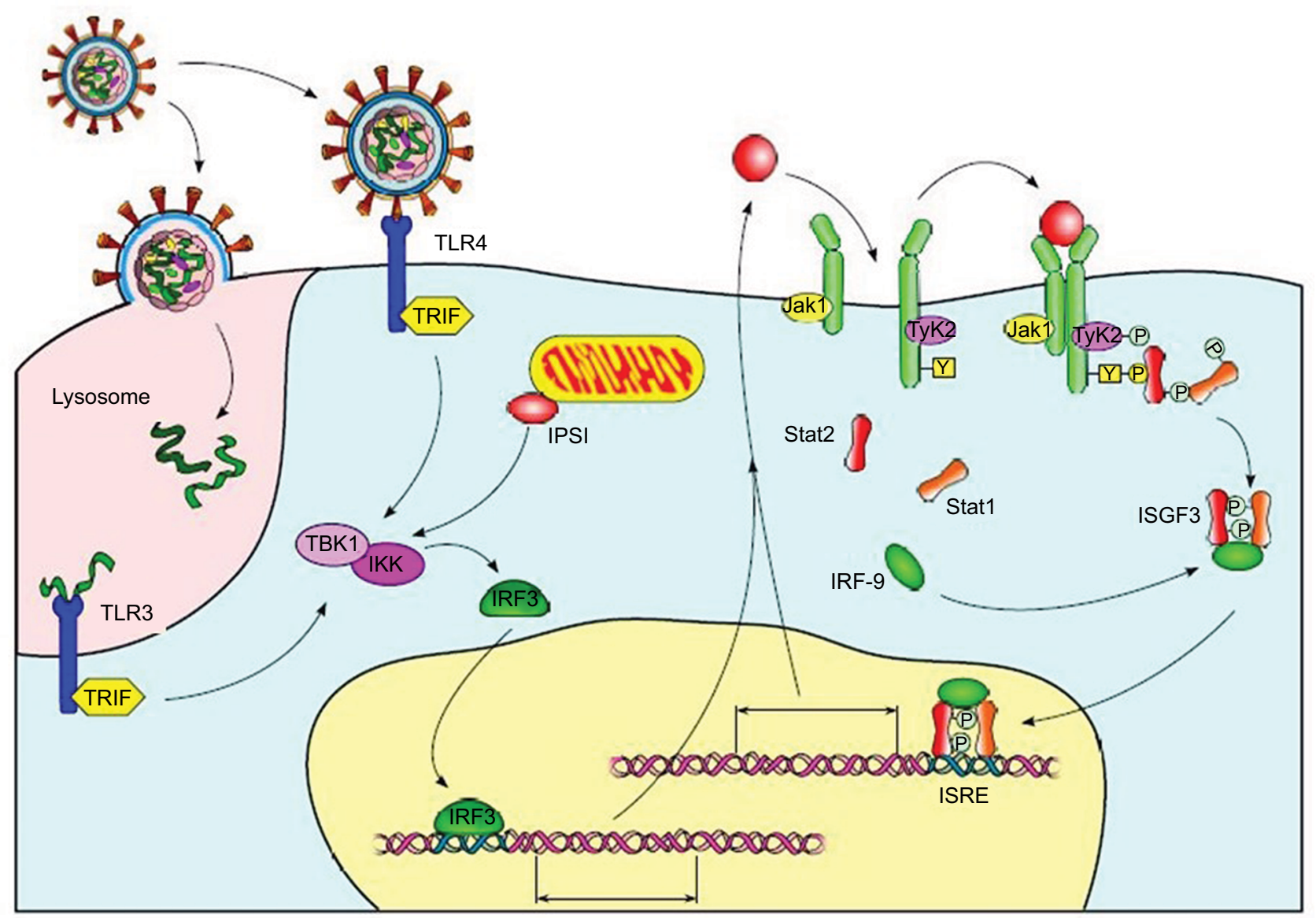

Figure 4 Mechanism of action of interferon in virus-infected cells.

Notes: When the cell senses viral presence, signaling pathways are triggered, which reach the nucleus. Certain molecules can stimulate ISRE, which activates the transcription of factors rendering the cell into an antiviral state. Data from Ballesteros. ${ }^{41}$

Abbreviations: ISRE, interferon-sensitive response element; IRF, interferon-response factor; ISGF, interferon-stimulated growth factor; TLR, toll-like receptor.

transient immunopathologic alterations. SRLVs have in vivo tropism for monocytes, macrophages, and dendritic cells. ${ }^{1}$ They can also infect microglia, ${ }^{1}$ endothelial cells, fibroblasts, and epithelial cells of other tissues, ${ }^{15-17}$ and these cells may act as reservoirs for the virus, as in the case of the epithelial cells of the mammary gland, and contribute to the transmission between the mother and the calf during lactation. ${ }^{1}$

The first targets for infection are macrophages and dendritic cells of the pulmonary or intestinal mucosae. Dendritic cells migrate to the lymph nodes where the virus is transferred to macrophages, which disseminate infection when they leave the lymph node. ${ }^{1}$ The monocyte/macrophage lineage represents a bridge between innate and adaptive immunities against SRLV. They act as antigen-presenting cells (APCs), processing the viral proteins. Replication in circulating monocytes and macrophages does not occur until the maturation of these cells in target organs. ${ }^{42}$ Therefore, monocytes and immature macrophages act as "Trojan horses", allowing the virus to escape the cellular and humoral immune responses. ${ }^{43}$
It is believed that infected macrophages penetrate to the bone marrow where they can affect myeloid or stromal cells, which would determine a continuous production of infected monocytes and would result in chronic infection throughout the life of the animal, ${ }^{1}$ though the bone marrow may not play a prominent role as virus reservoir. ${ }^{44}$ Infected macrophages express $e n v$ - and gag-encoded viral proteins on their surface, mostly associated with the major histocompatibility (MHC) complex. The viral proteins-MHC complex is recognized by $\mathrm{T}$ lymphocytes, stimulating the production of interferon (I and II). This attracts other inflammatory cells to the focus and maintains the viral replication cycle and chronic inflammation and may inhibit the maturation of monocytes to macrophages, therefore modulating viral replication. ${ }^{45}$ Chronic progressive inflammation is similar in all the target organs and is responsible for the clinical forms developed by the animals.

As regard to the humoral immune response, the first antibodies may appear 3 weeks after experimental infection 
and are against p25CA. Two weeks later, sheep and goats synthesize antibodies against gp46TM, p14NC, and p16MA. ${ }^{6}$ In most cases, antibodies against gp135SU are generated somewhat later. Antibodies generated against the Env proteins are interesting because they block the binding of these proteins to the cell receptor and have neutralizing ability, but neutralizing antibodies are produced slowly and have low affinity and their titers are low. ${ }^{1}$ In addition, there are uncertainties that they are functionally important in vivo, since SRLVs are cell-associated viruses and can spread by cell-to-cell contact, and neutralization may not interfere with viral spread. ${ }^{1,46}$ Even though the humoral response is not enough to eliminate the viral infection (which is lifelong lasting), some studies have shown that it limits the spread of the viruses. ${ }^{47}$ Antibodies do not always help fighting against the infection. Though the complex virion-antibody may be internalized by macrophages or dendritic cells, thanks to their Fc receptors for antibodies and, thus, conceivably anti-SRLV antibodies could favor infection; this possibility has not been unequivocally demonstrated. ${ }^{48}$

The cell-mediated immune responses against SRLVs start 1-4 weeks postinfection, but they are relatively weak and uncommon, in spite of the important role that the CTL defense plays against viral infections. Infected monocytes and macrophages can activate specific cytotoxic $\mathrm{T}$ cells. Immunopathologic alterations in target organs are partly due to the increase in $\mathrm{CD}^{+} \mathrm{T}$ cells and the inversion of the $\mathrm{CD} 4 / \mathrm{CD} 8$ ratio. Some co-stimulatory molecules, such as B7, appear to fail in MV and CAE since B7 transcripts and T-cell-specific memory responses in infected animals are significantly decreased ${ }^{49,50}$ in contrast to the increase observed during the asymptomatic phase of the infection. The consequence of this could be anergic $\mathrm{T}$ cells, unable to mount memory responses. This could involve the response to other antigens and be associated with immunodeficiency, affecting vaccination and defense against other pathogens. Thus, in spite of lymphocyte accumulation in some organs, possible anergy impedes defense against the virus.

A common observation is how erratic the antibody presence is. A general problem in diagnosis is that tests detecting antibodies against the SRLVs and the proviral genome may render opposite results. ${ }^{51-57}$ Though the discordances may be related to the diagnostic tests themselves, it is more probable that they are associated with the evolution of the antibodies and proviral shedding in the animal. Results of a study showed that the presence of antibodies and proviral DNA in milk samples from sheep and goats may change with time. This supports the suggestion that the combination of different tests for the diagnosis of SRLV may enhance the detection of infected animals and improve the efficacy of control and eradication campaigns. ${ }^{52,53}$

Sheep and goats respond differently to the infection, as judged by the presence of antibodies and proviral DNA in milk. In sheep, it seems that the presence of antibodies in the udder may decrease the detection of proviral DNA, which may not be the case with goats. In a study, a high percentage of sheep were Polymerase Chain Reaction (PCR) positive in milk before antibodies could be detected and most of them became PCR negative shortly after the first detection of antibodies. ${ }^{53}$ This might suggest that antibodies have a neutralizing effect. In addition, an equal percentage of sheep were always PCR negative in milk but either became ELISA positive or were always ELISA positive, which might suggest that the viral infection occurred in a different location than the udder and supported this hypothesis. In contrast, the PCR results in goats did not follow any pattern and oscillated between 35.3 and $55.6 \%$ of milk PCR-positive animals depending on the month. Most goats positive by PCR failed to develop antibodies in the 6 months of the experiment. ${ }^{53}$

In addition to the role of macrophages in the progress of infection, there are other events that modulate the evolution of the disease. As all retroviral infections, SRLV infection remains clinically latent or progresses very slowly for a period of time, which depends on the viral strain and, most importantly, on individual susceptibility and transcription triggering events. Regarding this latter factor, our group has studied the effect of steroid hormones on the expression of SRLVs, especially prompted by the observation that production and excretion of SRLVs vary with the stage of the sheep or goat reproductive cycle. ${ }^{18}$ Steroids act in a similar way to IFN mentioned earlier. They cross cell membranes by simple diffusion due to their lipophilic nature and bind to cytoplasmic receptors. The hormone-receptor complexes act as intracellular transcription factors that bind with high affinity to certain TBS called hormone response elements (HREs) present in the DNA (Figure 5). ${ }^{18} \mathrm{As}$ in the case of IFN, functional HREs have been identified in the LTR of SRLV. The overall tendency that we observed in our study was an inhibitory effect on expression as hormone concentrations increase. ${ }^{18}$ This is compatible with the in vivo observation of inhibitory effects (on virus activation) by the highest levels of progesterone during pregnancy, effects that disappeared at parturition when progesterone levels decreased and SRLV was activated. ${ }^{58}$

Though the exact events that trigger viral replication are not fully understood, there is a constant expression of viral proteins. The immune response generated against them causes 


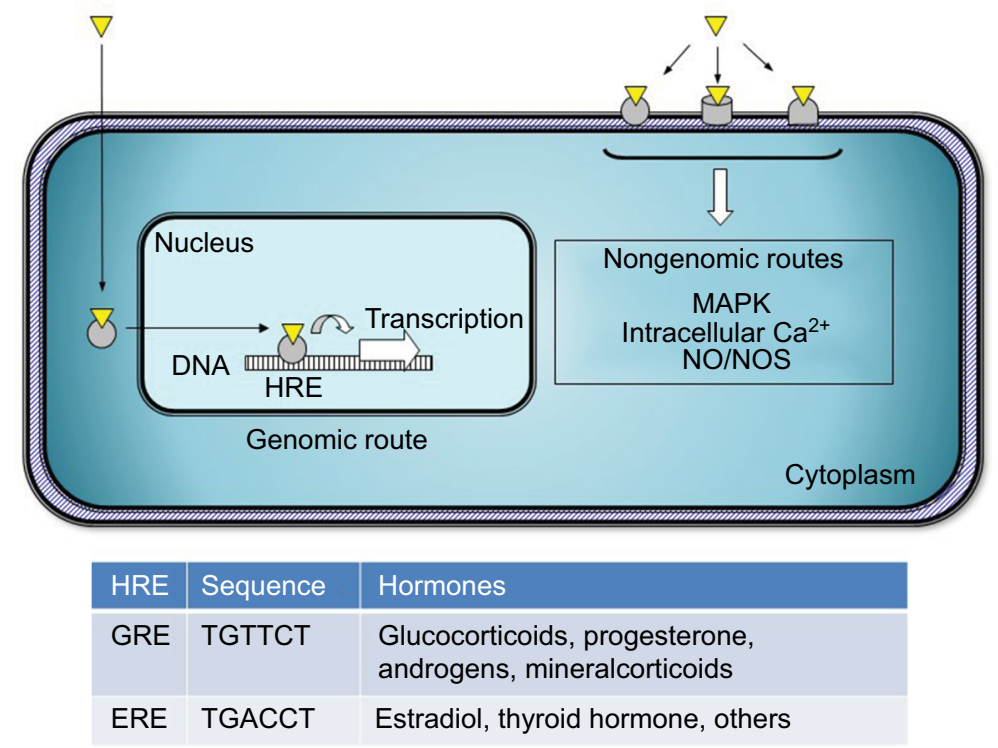

Figure $\mathbf{5}$ Stimulation of transcription by steroid hormones (represented by yellow triangles).

Notes: Steroid hormones are able to freely cross the plasma membrane and combine with the receptor (represented by gray forms). The best-studied mechanism involves that the hormone-receptor complexes cross the nuclear membrane and react with HREs, triggering transcription.

Abbreviations: HREs, hormone response elements; GRE, glucocorticoid responsive element; ERE, estrogen responsive element.

a chronic inflammation that leads to pathological changes observed in target tissues of the animals infected by SRLV. ${ }^{1}$ The main change that occurs in the affected tissues is the infiltration of mononuclear cells (lymphocytes, macrophages, and plasma cells) that are progressively organized into structures similar to lymphoid follicles and eventually destroy the normal tissue architecture and function of the affected organ. ${ }^{1}$

Maedi-Visna and CAE are characterized by respiratory, nervous, mammary, and joint clinical signs. The clinical affection appears to depend on the tropism of the SRLV strain, the species affected, and the genetic background of each breed or animal. Although the process is usually subclinical, a small percentage of animals may present some or all of these signs. Usually, respiratory and mammary signs are predominant in MV, while the nervous and joint signs are more important in CAE.

\section{Respiratory disease}

The respiratory disease is the most common clinical form in sheep. It affects adult animals older than 2 years, and once the symptoms are apparent, animal life expectancy does not exceed 1 year. ${ }^{59}$ The first phase of the disease is often overlooked, although it can be worsened by management deficiencies. Exercise intolerance is one of the first clinical signs to be noticed, followed by dyspnea at rest, accompanied by abdominal breathing, neck extension, expansion of the nostrils, and breathing with mouth open. ${ }^{46}$ As the disease progresses, the animal suffers from anorexia, weight loss, and finally cachexia. Nasal exudate appears only when there are secondary bacterial infections.

The main gross lesion is lung enlargement and increased weight. The disease affects the lungs and the regional lymph nodes. Chronically affected lungs are hypertrophic, up to three times the normal size, rounded, rubbery, grayish yellow, and with focal to diffuse miliary gray spots on the pulmonary pleural surface. These signs are accompanied by tumefaction (most evident in the mediastinal lymph nodes). If there are secondary bacterial infections, the cranioventral area may have reddish, moist-appearing regions and a marked lobular pattern. Gross pathology is similar to ovine pulmonary adenomatosis, and it is always recommendable to make a differential diagnosis. ${ }^{46}$

The clinical signs are caused by interstitial pneumonia that increases the thickness of the alveolar septa and progressively reduces the air exchange capacity of affected lungs. ${ }^{60}$ The interalveolar septa are infiltrated with lymphocytes, monocytes, macrophages, and plasma cells, which contributes to the thickening and hyperplasia of the smooth muscle fibers of the alveolar walls, favoring pulmonary dysfunction. Another characteristic lesion is diffuse lymphoid hyperplasia (mostly $\mathrm{CD} 4^{+}$and $\mathrm{CD} 8^{+} \mathrm{T}$ cells), ${ }^{61}$ responsible for the gray spots in the pleura mentioned earlier. As the disease progresses, the lesions become fibrotic. ${ }^{60,61}$

\section{Mammary disease}

The mammary disease is the second important form, due to economic losses and the frequency of occurrence. In some 
breeds (as in Rasa Aragonesa from Spain), it may be more frequent than the respiratory form. ${ }^{62}$ It generally affects adult animals aged between 3 and 5 years, but it has also been observed in 1-year-old animals. ${ }^{63}$ Our group has observed that it is more frequent in mechanical milking and in intensively reared animals. ${ }^{7}$ Mastitis usually is subclinical, indurative, chronic, diffuse, bilateral, and nonpainful, with swollen mammary lymph nodes. Milk production can be decreased and its macroscopic properties (color and consistency) do not vary. 6,7 Lesions are only apparent after lambing or kidding. Pathology reveals chronic interstitial mastitis characterized by infiltration of mononuclear cells around the mammary acini and milk ducts. This causes hyperplasia, vacuolization, and desquamation of the ductal epithelium. Finally, the lesion becomes fibrotic, causing mammary induration and stenosis of the milk duct.

\section{Joint disease}

Arthritis is the least common presentation in MV but frequent in CAE. It affects animals aged between 2 and 3 years. It usually affects the carpal and tarsal joints, so the process is marked by lameness. Also, the atlantal bursa and the nuchal ligament may be affected to a lesser extent. ${ }^{64,65}$ The process starts with edema and congestion of the synovial membrane and capsule of the joint, which causes both structures to thicken and enlarges joints. ${ }^{64,65}$ There is hardening of the periarticular tissue and synovial membrane proliferation, along with frequent erosions of the articular surfaces, which may even extend to bone destruction. ${ }^{65}$ Histology reveals papillary tissue projections of the synovial membrane into the articular space, with synoviocytes appearing hyperplasic, and erosion of the cartilage of the joint and the synovial fluid may appear cloudy. The synovial membrane proliferates and is sometimes detached. There is infiltration of mononuclear cells, mainly plasma cells, in the subsynovia, perivascular cuffs and connective tissue. ${ }^{65}$ Diffuse fibrosis of the capsule and other structures are common, and in severe cases, tissue necrosis may be observed, sometimes with dystrophic calcification and cartilaginous and/or osseous metaplasia. ${ }^{65}$ Finally, the arthrosis evolves to ankylosis due to calcification or fibrosis. Interestingly, goats with a Th2-biased CD4 ${ }^{+}$ T-cell response are known to develop arthritis, but those with a mixed IgG1 and IgG2 response remain without clinical signs, suggesting that anti-SRLV IgG2 antibodies protect against disease induction. ${ }^{66}$

\section{Nervous disease}

The nervous form is very rare in sheep, where it is mostly seen in stabled animals. It affects animals aged $>2$ years, although in some breeds such as Assaf it may occur in younger animals. Recently, an extensive outbreak of MVV infection in Northwest Spain has been diagnosed (even in animals aged 4-6 months). ${ }^{67}$ Nervous signs include hind-limb weakness and ataxia, hypermetria, and paralysis, usually leading to recumbence, although the animal remains alert and responds to external stimuli. ${ }^{68}$ The main lesion is encephalitis or encephalomyelitis. ${ }^{68,69}$ Chronic nonpurulent meningoencephalomyelitis, usually accompanied by demyelination, is common. Sometimes there is also mononuclear infiltration of the choroid plexus, which sometimes results in the development of ectopic lymphoid follicles. ${ }^{70}$ The following three main patterns may be observed: vascular pattern, with mononuclear cells around blood vessels forming perivascular cuffs; infiltrative pattern, characterized by nonpurulent infiltration of the neuroparenchyma and perivascular cuffing; and malacic pattern, with demyelination. ${ }^{69}$

In goats, it is less frequent than the articular form and it is characterized by leukoencephalomyelitis in 2-6-month-old kids. ${ }^{64}$ The syndrome includes incoordination, ataxia of the hind limbs, which eventually may also affect the front limbs, and finally prostration and paralysis. ${ }^{64}$ These clinical signs are present for 6 months to a year, accompanied, as in the rest of forms, by progressive thinning and, in some cases, cachexia. ${ }^{64}$

The final phase of the pathogenesis begins when the clinical illness develops. At this point, and depending on the clinical form, the animal may die soon or remain chronically affected. ${ }^{1}$ Despite the high level of infection in some herds, the clinical manifestations may not be very apparent, as there are many factors that influence pathogenesis. These include the viral strain, age and breed of the animal, the route of exposure, possible secondary infections, and management conditions.

\section{Infection at the flock level - can we help?}

At the flock level, many factors have been identified that affect disease progression, which are grouped under risk factors. Of the many factors, some of them can be explained through other main ones, which include flock size (being 70 dams the limit above which there is an increased risk for lentiviral infection $)^{71}$ and type of management system (SRLV seroprevalence has been found higher in intensively reared sheep than in semi-intensively and extensively reared sheep). ${ }^{7,8,71,72}$ The infection rate of the animals translates directly to an impaired physical condition. ${ }^{71}$ In a study that we conducted, all productivity parameter measures appeared to be reduced in the seropositive groups for both goats and 
sheep, even though the differences were not statistically significant. $^{7}$

There is no vaccine or treatment effective against SRLV infections. Thus, reducing the burden of the clinical signs and economic losses relies on management measures, including marker-assisted selective breeding. Certain breeds have been associated consistently with higher (eg, Columbia sheep) or lower (eg, Rambouillet) odds of infection. ${ }^{73}$ Also, breed differences in prevalence and proviral concentration indicate a strong genetic basis for susceptibility to infection by SRLV in sheep. Animals with high blood proviral concentration show increased tissue lesion severity, so proviral concentration represents a live animal test for control postinfection in terms of proviral replication and disease severity. ${ }^{44,74}$

\section{Ovine transmembrane protein 154 (TMEMI54)}

Recent studies have evidenced that certain haplotypes of the gene encoding TMEM154, an ovine transmembrane protein, are associated with the infection of sheep to MVV. ${ }^{75}$ Specifically, polypeptide variants that contain glutamic acid (E) at position 35 and asparagine $(\mathrm{N})$ at position 70 (variant 3), or E35 and isoleucine (I) at position 70 (variant 2) in the ancestral, full-length version of the protein, are associated with increased susceptibility to the lentivirus, whereas polypeptide variants that contain lysine $(\mathrm{K})$ at position 35 or deletion mutants are associated with reduced susceptibility. Sheep homozygous for haplotype 1 were less susceptible to SRLV infection, but sheep with at least one copy of either haplotype 2 or haplotype 3 were 69 times more susceptible. ${ }^{75,76}$ In addition, possibly, sheep homozygous for TMEM154 haplotype 1 may also have lower proviral concentrations and lesion severity among infected sheep and would be less likely to spread the infection to other sheep. ${ }^{77}$ The most susceptible haplotypes are distributed worldwide suggesting that genetic testing and removing sheep with the most susceptible TMEM154 alleles may help eradicate MVV and protect flocks from reinfection, improving the health and productivity of infected flocks. ${ }^{76}$ An assay aimed at identifying these susceptible alleles has been recently devised. ${ }^{76}$

The ancestral TMEM154 haplotype in sheep is common and predicted to encode a precursor protein of 191 amino acids that is cleaved to a mature protein with 161 residues. ${ }^{76}$ However, little is known about the function of TMEM154. An equivalent to the ovine polyprotein has been associated in humans with asthma severity, suggesting a possible conserved role in airway immunity. ${ }^{77}$

\section{Conclusion}

There are different mechanisms that make the success of the infection by SRLV difficult. The host can display an array of strategies both at the cell and organism levels. In addition, some genetic traits can be exploited to raise more resistant breeds. A deeper knowledge on how they act may help improve the health of our flocks, making them more profitable and sustainable.

\section{Acknowledgments}

The authors are indebted to David A Bruhn for his critical review of the article. This study was supported by Spanish AGL2008-04240/GAN and UCM 920620-BSCH-UCM GR58/08.

\section{Disclosure}

The authors report no conflicts of interest in this work.

\section{References}

1. Blacklaws BA. Small ruminant lentiviruses: immunopathogenesis of Visna-Maedi and caprine arthritis and encephalitis virus. Comp Immunol Microbiol Infect Dis. 2012;35(3):259-269.

2. Souza TS, Pinheiro RR, Costa JN, et al. Interspecific transmission of small ruminant lentiviruses from goats to sheep. Braz J Microbiol. 2015;46(3):867-874.

3. Germain K, Valas S. Distribution and heterogeneity of small ruminant lentivirus envelope subtypes in naturally infected French sheep. Virus Res. 2006;120(1-2):156-162.

4. Leroux C, Chastang J, Greenland T, Mornex JF. Genomic heterogeneity of small ruminant lentiviruses: existence of heterogeneous populations in sheep and of the same lentiviral genotypes in sheep and goats. Arch Virol. 1997;142(6):1125-1137.

5. Oguma K, Tanaka C, Harasawa R, et al. Isolation of Maedi/Visna virus from a sheep in Japan. J Vet Med Sci. 2014;76(2):211-218.

6. de la Concha-Bermejillo A. Maedi-Visna and ovine progressive pneumonia. Vet Clin North Am Food Anim Pract. 1997;13(1):13-33.

7. Barquero N, Gomez-Lucia E, Arjona A, et al. Investigation of risk factors associated with infections caused by small ruminant lentiviruses. Bull Vet Inst Pulawy. 2013;57(4):473-478.

8. Leginagoikoa I, Minguijón E, Juste RA, et al. Effects of housing on the incidence of Visna/Maedi virus infection in sheep flocks. Res Vet Sci. 2010;88(3):415-421.

9. Narayan O, Sheffer D, Clements JE, Tennekoon G. Restricted replication of lentiviruses. Visna viruses induce a unique interferon during interaction between lymphocytes and infected macrophages. $J$ Exp Med. 1985;162(6):1954-1969.

10. Blacklaws BA, Berriatua E, Torsteinsdottir S, et al. Transmission of small ruminant lentiviruses. Vet Microbiol. 2004;101(3):199-208.

11. Péretz G, Bugnard F, Calavas D. Study of a prevention programme for caprine arthritis-encephalitis. Vet Res. 1994;25(2-3):322-326.

12. Shah C, Huder JB, Böni J, et al. Direct evidence for natural transmission of small-ruminant lentiviruses of subtype A4 from goats to sheep and vice versa. J Virol. 2004;78(14):7518-7522.

13. Glaria I, Reina R, Ramírez H, et al. Visna/Maedi virus genetic characterization and serological diagnosis of infection in sheep from a neurological outbreak. Vet Microbiol. 2012;155(2-4):137-146.

14. Pépin M, Vitu C, Russo P, Mornex JF, Peterhans E. Maedi-Visna virus infection in sheep: a review. Vet Res. 1998;29(3-4):341-367. 
15. Adedeji AO, Barr B, Gomez-Lucia E, Murphy B. A polytropic caprine arthritis encephalitis virus promoter isolated from multiple tissues from a sheep with multisystemic lentivirus-associated inflammatory disease. Viruses. 2013;5(8):2005-2018.

16. Hötzel I, Cheevers W. Differential receptor usage of small ruminant lentiviruses in ovine and caprine cells: host range but not cytopathic phenotype is determined by receptor usage. Virology. 2002;301(1): 21-31.

17. Murphy B, McElliott V, Vapniarsky N, Oliver A, Rowe J. Tissue tropism and promoter sequence variation in caprine arthritis encephalitis virus infected goats. Virus Res. 2010;151(2):177-184.

18. Gomez-Lucia E, Sanjosé L, Crespo O, et al. Modulation of the long terminal repeat promoter activity of small ruminant lentiviruses by steroids. Vet J. 2014;202(2):323-328.

19. Agnarsdóttir $\mathrm{G}$, Thorsteinsdóttir $\mathrm{H}$, Oskarsson $\mathrm{T}$, et al. The long terminal repeat is a determinant of cell tropism of Maedi-Visna virus. $J$ Gen Virol. 2000;81(pt 8):1901-1905.

20. Bertoni G, Zahno ML, Zanoni R, et al. Antibody reactivity to the immunodominant epitopes of the caprine arthritis-encephalitis virus gp38 transmembrane protein associates with the development of arthritis. JVirol. 1994;68(11):7139-7147.

21. Rosati S, Pittau M, Tolari F, Erre G, Kwang J. Genetic and antigenic characterization of CAEV (caprine arthritis-encephalitis virus) recombinant transmembrane protein. Vet Microbiol. 1995;45(4):363-370.

22. Franzdóttir SR, Ólafsdóttir K, Jónsson SR, Strobel H, Andrésson ÓS, Andrésdóttir V. Two mutations in the vif gene of Maedi-Visna virus have different phenotypes, indicating more than one function of Vif. Virology. 2016;488:37-42.

23. Jónsson SR, Andrésdóttir V. Host restriction of lentiviruses and viral countermeasures: APOBEC3 and Vif. Viruses. 2013;5(8):1934-1947.

24. Yoshikawa R, Izumi T, Nakano Y, et al. Small ruminant lentiviral Vif proteins commonly utilize cyclophilin A, an evolutionarily and structurally conserved protein, to degrade ovine and caprine APOBEC3 proteins. Microbiol Immunol. 2016;60(6):427-436.

25. Zhang J, Wu J, Wang W, et al. Role of cullin-elonginB-elonginC E3 complex in bovine immunodeficiency virus and Maedi-Visna virus Vif-mediated degradation of host A3Z2-Z3 proteins. Retrovirology. 2014;11:77.

26. Villet S, Bouzar BA, Morin T, Verdier G, Legras C, Chebloune Y. MaediVisna virus and caprine arthritis encephalitis virus genomes encode a Vpr-like but no Tat protein. J Virol. 2003;77(17):9632-9638.

27. Crespo H, Reina R, Glaria I, et al. Identification of the ovine mannose receptor and its possible role in Visna/Maedi virus infection. Vet Res. 2011;42(1):28.

28. Jauregui P, Crespo H, Glaria I, et al. Ovine TRIM5 can restrict Visna/ Maedi virus. J Virol. 2012;86(17):9504-9509.

29. Harris RS, Dudley JP. APOBECs and virus restriction. Virology. 2015;479-480:131-145.

30. de Pablo-Maiso L, Glaria I, Crespo H, et al. Characterization of ovine A3Z1 restriction properties against small ruminant lentiviruses (SRLVs). Viruses. 2017;9(11):345.

31. Esparza-Baquer A, Larruskain A, Mateo-Abad M, et al. SNPs in APOBEC 3 cytosine deaminases and their association with Visna/Maedi disease progression. Vet Immunol Immunopathol. 2015;163(3-4):125-133.

32. Kristbjörnsdóttir HB, Andrésdóttir V, Svansson V, Torsteinsdóttir S, Matthíasdóttir S, Andrésson ÓS. The vif gene of Maedi-Visna virus is essential for infectivity in vivo and in vitro. Virology. 2004;318(1):350-359.

33. Kane JR, Stanley DJ, Hultquist JF, et al. Lineage-specific viral hijacking of non-canonical E3 ubiquitin ligase cofactors in the evolution of Vif anti-APOBEC3 activity. Cell Rep. 2015;11(8):1236-1250.

34. Ai Y, Zhu D, Wang C, et al. Core-binding factor subunit beta is not required for non-primate lentiviral Vif-mediated APOBEC3 degradation. J Virol. 2014;88(20):12112-12122.

35. Blaszczyk K, Nowicka H, Kostyrko K, Antonczyk A, Wesoly J, Bluyssen HAR. The unique role of STAT2 in constitutive and IFN-induced transcription and antiviral responses. Cytokine Growth Factor Rev. 2016;29:71-81.
36. Añez Regidor R. Modulación de la actividad transcripcional del LTR del virus de la artritis encefalitis caprina mediada por interferones tipo I y tipo II. Trabajo Fin de Máster en Virología [Modulation of the transcriptional activity of the LTR of the caprine arthritis encephalitis virus mediated by type I and type II interferons]. Madrid: Complutense University of Madrid. [Masters thesis]. 2013.

37. Juganaru M, Reina R, Grego E, Profiti M, Rosati S. LTR promoter activity of SRLV genotype E, strain Roccaverano. Vet Res Commun. 2010;34(suppl 1):S47-S51.

38. Murphy B, Hillman C, Castillo D, Vapniarsky N, Rowe J. The presence or absence of the gamma-activated site determines IFN gamma-mediated transcriptional activation in CAEV promoters cloned from the mammary gland and joint synovium of a single CAEV-infected goat. Virus Res. 2012;163(2):537-545.

39. Gomez-Lucia E, Rowe J, Collar C, Murphy B. Diversity of caprine arthritis-encephalitis virus promoters isolated from goat milk and passaged in vitro. Vet J. 2013;196(3):431-438.

40. Gómez-Lucía E, Collado VM, Miró G, Doménech A. Effect of type-I interferon on retroviruses. Viruses. 2009;1(3):545-573.

41. Ballesteros N. Estudios in vitro del interferón tipo I (A/D) en células coinfectadas con FIV y FeLV y la interacción de la región promotora (LTR) de MVV en células transfectadas con un plásmido recombinante. Madrid: Universidad Complutense de Madrid [In vitro studies of interferon type I (A/D) in cells coinfected with FIV and FeLV and interaction of the promoter region (LTR) of MVV in cells transfected with a recombinant plasmid. Madrid: Complutense University of Madrid]. [Master Thesis]; 2011.

42. Narayan O, Kennedy-Stoskopf S, Sheffer D, Griffin DE, Clements JE. Activation of caprine arthritis-encephalitis virus expression during maturation of monocytes to macrophages. Infect Immun. 1983;41(1):67-73.

43. Peluso R, Haase A, Stowring L, Edwards M, Ventura P. A Trojan Horse mechanism for the spread of Visna virus in monocytes. Virology. 1985;147(1):231-236.

44. Ravazzolo AP, Nenci C, Vogt H-R, et al. Viral load, organ distribution, histopathological lesions, and cytokine mRNA expression in goats infected with a molecular clone of the caprine arthritis encephalitis virus. Virology. 2006;350(1):116-127.

45. Zink MC, Narayan O. Lentivirus-induced interferon inhibits maturation and proliferation of monocytes and restricts the replication of caprine arthritis-encephalitis virus. J Virol. 1989;63(6):2578-2584.

46. Barquero N, Domenech A, Gomez-Lucia E. Infections by Small Ruminant Lentiviruses. Saarbrücken, Germany: LAP Lambert Academic Publishing; 2015.

47. Andrésdóttir V, Skraban R, Matthíasdóttir S, Lutley R, Agnarsdóttir G, Thorsteinsdóttir H. Selection of antigenic variants in Maedi-Visna virus infection. J Gen Virol. 2002;83(pt 10):2543-2551.

48. Jolly PE, Huso D, Hart G, Narayan O. Modulation of lentivirus replication by antibodies. Non-neutralizing antibodies to caprine arthritisencephalitis virus enhance early stages of infection in macrophages, but do not cause increased production of virions. J Gen Virol. 1989;70(pt 8):2221-2226.

49. Reina R, Glaria I, Benavides J, et al. Association of CD80 and CD86 expression levels with disease status of Visna/Maedi virus infected sheep. Viral Immunol. 2007;20(4):609-622.

50. Larruskain A, Jugo BM. Retroviral infections in sheep and goats: small ruminant lentiviruses and host interaction. Viruses. 2013;5(8):2043-2061.

51. Clements JE, Zink MC. Molecular biology and pathogenesis of animal lentivirus infections. Clin Microbiol Rev. 1996;9(1):100-117.

52. Barquero N, Arjona A, Domenech A, et al. Diagnostic performance of PCR and ELISA on blood and milk samples and serological survey for small ruminant lentiviruses in central Spain. Vet Rec. 2011;168(1):20.

53. Barquero N, Gomez-Lucia E, Arjona A, et al. Evolution of specific antibodies and proviral DNA in milk of small ruminants infected by small ruminant lentivirus. Viruses. 2013;5(10):2614-2623.

54. Brodie SJ, Pearson LD, Snowder GD, DeMartini JC. Host-virus interaction as defined by amplification of viral DNA and serology in lentivirus-infected sheep. Arch Virol. 1993;130(3-4):413-428. 
55. Celer V Jr, Celer V, Nejedlá E, Bertoni G, Peterhans E, Zanoni RG. The detection of proviral DNA by semi-nested polymerase chain reaction and phylogenetic analysis of Czech Maedi-Visna isolates based on gag gene sequences. JVet Med B Infect Dis Vet Public Health. 2000;47(3):203-215.

56. Kuzmak J, Kedziora A, Rola M, Kozaczynska B, Chebloune Y, Gallay K. Evaluation of PCR and PCR/hybridization method for the detection of caprine arthritis-encephalitis virus infection in goats. B Vet Pulawy. 2003;47:293-300.

57. de Andrés D, Klein D, Watt NJ, et al. Diagnostic tests for small ruminant lentiviruses. Vet Microbiol. 2005;107(1-2):49-62.

58. Lerondelle C, Ouzrout R. Expression of Maedi-Visna virus in mammary secretions of a seropositive ewe. Dev Biol Stand. 1990;72:223-227.

59. Watt NJ, King TJ, Collie D, McIntyre N, Sargan D, McConnell I. Clinicopathological investigation of primary, uncomplicated Maedi-Visna virus infection. Vet Rec. 1992;131(20):455-461.

60. Minguijón E, Reina R, Pérez M, et al. Small ruminant lentivirus infections and diseases. Vet Microbiol. 2015;181(1-2):75-89.

61. Luján L, Begara I, Collie DD, Watt NJ. CD8+ lymphocytes in bronchoalveolar lavage and blood: in vivo indicators of lung pathology caused by Maedi-Visna virus. Vet Immunol Immunopathol. 1995;49(1-2):89-100.

62. Luján L, García Marin JF, Fernández de Luco D, Vargas A, Badiola JJ. Pathological changes in the lungs and mammary glands of sheep and their relationship with Maedi-Visna infection. Vet Rec. 1991;129(3):51-54.

63. Houwers DJ, Nauta IM. Immunoblot analysis of the antibody response to ovine lentivirus infections. Vet Microbiol. 1989;19(2):127-139.

64. Rowe JD, East NE. Risk factors for transmission and methods for control of caprine arthritis-encephalitis virus infection. Vet Clin North Am Food Anim Pract. 1997;13(1):35-53.

65. Pérez M, Biescas E, Reina R, et al. Small ruminant lentivirus-induced arthritis: clinicopathologic findings in sheep infected by a highly replicative SRLV B2 genotype. Vet Pathol. 2015;52(1):132-139.

66. Cheevers WP, Beyer JC, Knowles DP. Type 1 and type 2 cytokine gene expression by viral gp135 surface protein-activated T lymphocytes in caprine arthritis-encephalitis lentivirus infection. J Virol. 1997;71(8):6259-6263.
67. Benavides J, García-Pariente C, Ferreras MC, Fuertes M, García-Marín JF, Pérez V. Diagnosis of clinical cases of the nervous form of MaediVisna in 4- and 6-month-old lambs. Vet J. 2007;174(3):655-658.

68. Benavides J, Fuertes M, García-Pariente C, Ferreras MC, García Marín JF, Pérez V. Natural cases of Visna in sheep with myelitis as the sole lesion in the central nervous system. J Comp Pathol. 2006;134(2-3): 219-230.

69. Benavides J, García-Pariente C, Fuertes M, et al. Maedi-Visna: the meningoencephalitis in naturally occurring cases. J Comp Pathol. 2009;140(1): $1-11$.

70. Cutlip RC, Jackson TA, Lehmkuhl HD. Lesions of ovine progressive pneumonia: interstitial pneumonitis and encephalitis. Am J Vet Res. 1979;40(10):1370-1374.

71. Junkuszew A, Dudko P, Bojar W, et al. Risk factors associated with small ruminant lentivirus infection in eastern Poland sheep flocks. Prev Vet Med. 2016;127:44-49.

72. Pérez M, Biescas E, de Andrés X, et al. Visna/Maedi virus serology in sheep: survey, risk factors and implementation of a successful control programme in Aragón (Spain). Vet J. 2010;186(2):221-225.

73. White SN, Knowles DP. Expanding possibilities for intervention against small ruminant lentiviruses through genetic marker-assisted selective breeding. Viruses. 2013;5(6):1466-1499.

74. Herrmann-Hoesing LM, Noh SM, White SN, Snekvik KR, Truscott T, Knowles DP. Peripheral ovine progressive pneumonia provirus levels correlate with and predict histological tissue lesion severity in naturally infected sheep. Clin Vaccine Immunol. 2009;16(4):551-557.

75. Heaton MP, Clawson ML, Chitko-Mckown CG, et al. Reduced lentivirus susceptibility in sheep with TMEM154 mutations. PLoS Genet. 2012;8(1):e1002467.

76. Heaton MP, Kalbfleisch TS, Petrik DT, et al. Genetic testing for TMEM154 mutations associated with lentivirus susceptibility in sheep. PLoS One. 2013;8(2):e55490.

77. Alshanbari FA, Mousel MR, Reynolds JO, et al. Mutations in Ovis aries TMEM154 are associated with lower small ruminant lentivirus proviral concentration in one sheep flock. Anim Genet. 2014;45(4):565-571.
Veterinary Medicine: Research and Reports

\section{Publish your work in this journal}

Veterinary Medicine: Research and Reports is an international, peer-reviewed, open access journal publishing original research, case reports, editorials, reviews and commentaries on all areas of veterinary medicine. The manuscript management system is completely online and includes a very quick and fair peer-review system.

\section{Dovepress}

Visit http://www.dovepress.com/testimonials.php to read real quotes from published authors.

Submit your manuscript here: http://www.dovepress.com/veterinary-medicine-research-and-reports-journal 